\title{
Large-scale aluminum foam plate fabricated by enhanced friction powder compaction process based on sintering and dissolution process
}

\author{
Yoshihiko Hangai $^{\mathrm{a}, *}$, Kousuke Zushida ${ }^{\mathrm{a}}$, Osamu Kuwazuru ${ }^{\mathrm{b}}$ and Nobuhiro Yoshikawa ${ }^{\mathrm{c}}$ \\ ${ }^{\text {a }}$ Faculty of Science and Technology, Gunma University, Kiryu 376-8515, Japan \\ ${ }^{\mathrm{b}}$ Graduate School of Engineering, University of Fukui, Fukui 910-8507, Japan \\ c Institute of Industrial Science, The University of Tokyo, Tokyo 153-8505, Japan
}

\begin{abstract}
An enhanced friction powder compaction (FPC) process was proposed for fabricating a large plate of aluminum foam by the sintering and dissolution process. In this process, the rotating tool plunged into the die filled with a powder mixture of aluminum and $\mathrm{NaCl}$ during the FPC process was made to traverse perpendicularly to the direction of plunging as in the case of friction stir welding. In the enhanced FPC process, no external heat source, such as an electric furnace or a spark plasma sintering, was necessary for fabricating aluminum foam, except for the friction heat generated by traversing the rotating tool. It was found that a long plate of aluminum foam can be fabricated with a length equal to the tool traversing length. By X-ray computed tomography (CT) and scanning electron microscopy (SEM) observations of the pore structures of the fabricated aluminum foam, it was found that the entire sample had a pore structures that was similar to the $\mathrm{NaCl}$ morphology, regardless of the position along the traversing direction. The fabricated aluminum foam had a similar stress-strain curve to that of aluminum foam fabricated by spark plasma sintering and exhibited ductile fracture. This is considered to be attributed to the good bonding between aluminum particles in the entire sample. The fabricated aluminum foam exhibited almost the same plateau stress regardless of the position along the traversing direction.
\end{abstract}


Keywords : cellular materials; powder metallurgy; sintering; friction stir welding; X-ray computed tomography

* Corresponding author.

E-mail: hanhan@gunma-u.ac.jp

Tel: +81-277-30-1554 


\section{Introduction}

Aluminum foam has the potential to be used in automotive, railway and construction industries, owing to its lightweight and specific energy absorption and sound insulation properties. Several processing routes have been proposed for fabricating aluminum ( $\mathrm{Al})$ foam as reviewed by Banhart (2001). Among these processing routes, the space holder method is a promising route, because the pore structures (porosity, pore size and pore distribution) could be easily controlled and hence the properties of the $\mathrm{Al}$ foam. Zhao and Sun (2001) have developed a novel space holder method called the sintering and dissolution process for fabricating open-cell $\mathrm{Al}$ foam, on the basis of powder metallurgy. In this process, a powder mixture of $\mathrm{Al}$ and sodium chloride $(\mathrm{NaCl})$ is first sintered by applying appropriate pressure and heat in an electric furnace as demonstrated by Surace et al. (2009) or by spark plasma sintering (SPS) as demonstrated by Hakamada et al. (2007). Thereafter, the sintered mixture is placed in water to dissolve the $\mathrm{NaCl}$, resulting in the formation of pores in the $\mathrm{Al}$ matrix. It is considered that $\mathrm{NaCl}$ retains its shape during the sintering of $\mathrm{Al}$ particles because the melting point of $\mathrm{Al}$ is lower than that of $\mathrm{NaCl}$. The advantage of the sintering and dissolution process is that $\mathrm{Al}$ foam with controlled pore structures can be fabricated using $\mathrm{NaCl}$, which is low in cost, readily available, nontoxic, and rapidly dissolves in water at room temperature. However, the Al foam fabricated by the sintering and dissolution process shows size limitation. Namely, the specifications of the electric furnace or SPS equipment restrict the size of the fabricated Al foam. For an intermetallic foam, Kobashi et al. (2013) developed a technique combining a self-propagating combustion reaction process and the sintering and dissolution process for fabricating TiAl foam with bimodal pore size distribution using $\mathrm{NaCl}$. Arakawa et al. (2013) found that the self-propagating combustion reaction process has the potential for fabricating a long block of TiAl foam. Therefore, the technique combining the self-propagating combustion reaction process and the sintering 
and dissolution process has the potential for fabricating a large block of intermetallic foam with controlled pore structures. However, there are few research studies related to the fabrication of a large block of $\mathrm{Al}$ foam with controlled pore structures.

Recently, a new friction powder compaction (FPC) process, which does not require any external heat sources, for fabricating metal foam by the sintering and dissolution process, has been developed by Hangai et al. (2013a) and Hangai et al. (2013b). In this process, the powder mixture is sintered by applying only friction heat and a pressing load, which is generated only by a rotating tool plunged into a die filled with the mixture. It is expected that a large $\mathrm{Al}$ foam plate can be obtained by the enhanced FPC process, in which the plunged rotating tool is made to traverse perpendicularly to the direction of plunging, as in the cases of friction stir welding and friction stir processing, which has been proposed by Hangai and Zushida (2013).

Mishra et al. (2003) developed a novel friction stir processing based on friction stir welding for fabricating $\mathrm{Al}-\mathrm{SiC}$ composites by mixing $\mathrm{SiC}$ particles as reinforcements into Al plates. Since then, the friction stir processing has been used for mixing powder into bulk metals such as Fullerene/A5083 composites fabricated by Morisada et al. (2007), Al powder was added to the gap between A1050 aluminum plates to prevent the generation of defect by Inada et al. (2010), $\mathrm{Al}_{3} \mathrm{Ni}$ particulate-reinforced composites were fabricated by introduced Ni powder into 1100 aluminum plates by Qian et al. (2012), AA6360/(TiC+B4C) hybrid surface composite layer fabricated by Rejil et al. (2012) and TiCp/Ti-6Al-4V surface composite fabricated by Li et al. (2013). However, no work has been done for the direct compaction and sintering of a powder by friction stir welding and friction stir processing.

In this study, a long $\mathrm{Al}$ foam plate was fabricated by the enhanced FPC process. The pore structures of the fabricated $\mathrm{Al}$ foam plate were nondestructively observed by X-ray computed tomography (CT) and scanning electron microscopy (SEM) to confirm 
whether their shape is similar to that of $\mathrm{NaCl}$ particles throughout the entire $\mathrm{Al}$ foam plate regardless of the position along the traversing direction. The compression tests of the obtained $\mathrm{Al}$ foam were conducted and the results were compared with those of the $\mathrm{Al}$ foam fabricated by the ordinary sintering and dissolution process to confirm whether good bonding between Al particles is achieved and whether uniform compression properties are obtained for the entire $\mathrm{Al}$ foam plate regardless of the position along the traversing direction.

\section{Experimental procedure}

\subsection{Materials and Methods}

Fig. 1 shows the schematic of the enhanced FPC process for fabricating a long Al foam plate. Commercially available, as-received $\mathrm{Al}$ (99.9\% purity, average diameter of $20 \mu \mathrm{m})$ and sieved $\mathrm{NaCl}(99.9 \%$ purity, diameter range from $300 \mu \mathrm{m}$ to $425 \mu \mathrm{m})$ powders were used as the starting materials. Fig. 2 shows SEM images of the Al and $\mathrm{NaCl}$ powders, and reveals that the $\mathrm{Al}$ particles had an irregular but relatively elongated
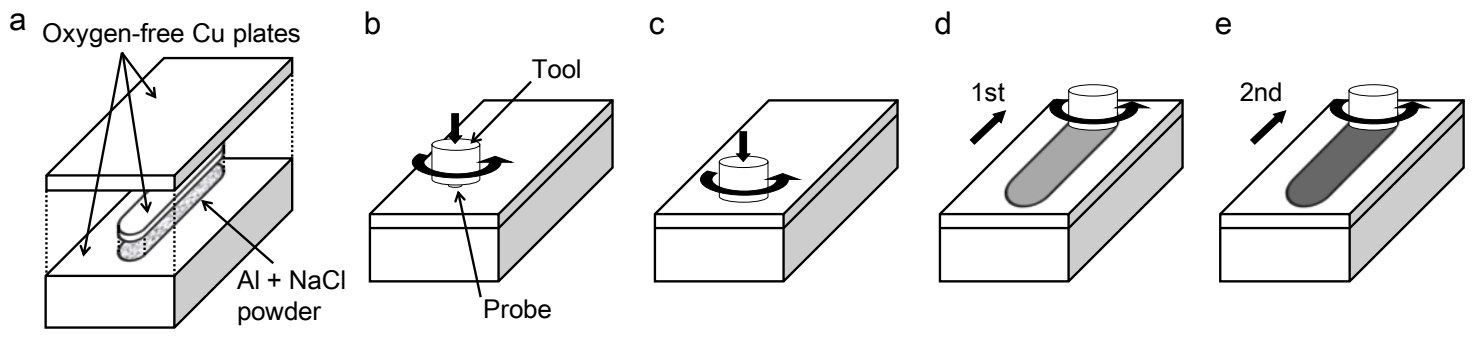

Fig. 1. Schematic of enhanced FPC process based on sintering and dissolution process for fabricating long $\mathrm{Al}$ foam plate. 

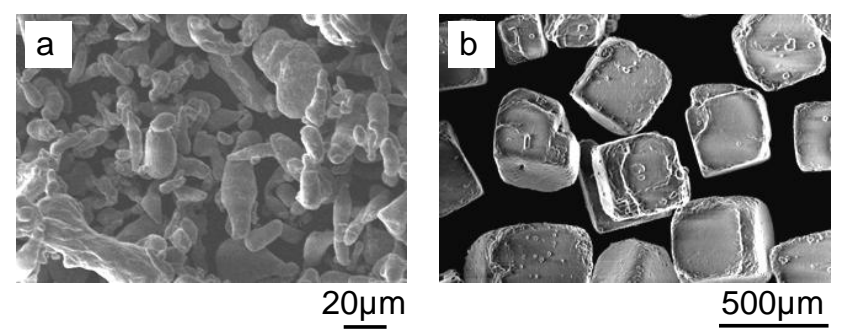

Fig. 2. SEM images of starting materials: (a) Al powder particles and (b) $\mathrm{NaCl}$ powder particles.

shape, while the $\mathrm{NaCl}$ particles were cuboidal. These powders were thoroughly mixed at a specific weight ratio with a $\mathrm{NaCl}$ volume fraction of $70 \%$. The $\mathrm{NaCl}$ powder was heated to $433 \mathrm{~K}$ for $30 \mathrm{~min}$ to remove the moisture from it before mixing. As shown in Fig. 1(a), the mixture was placed in a groove of $60 \mathrm{~mm}$ length, $10 \mathrm{~mm}$ width and $7 \mathrm{~mm}$ depth with rounded corners of $5 \mathrm{~mm}$ radius in the middle of a die made from an oxygen-free copper $(\mathrm{Cu})$ plate of $10 \mathrm{~mm}$ thickness. The $\mathrm{Cu}$ plate was used as a die to achieve high sintering temperature and load, as discussed by Hangai et al. (2013a). Then, an oxygen-free $\mathrm{Cu}$ plate of $2 \mathrm{~mm}$ thickness, whose shape was the same as the groove, was positioned on top of the mixture as the cover plate of the groove to prevent the mixture from being ejected from the groove. Thereafter, another oxygen-free $\mathrm{Cu}$ plate of $3 \mathrm{~mm}$ thickness was stacked to fix the groove-shaped cover plate from being inclined and ejected from the groove, and to increase the amount of friction heat generated during the traversing of the rotating tool. An SS400 back plate of $3 \mathrm{~mm}$ thickness was placed under the $\mathrm{Cu}$ plate die. Next, as shown in Fig. 1(b), a rotating tool made of tungsten carbide, which had a cylindrical shape and a short probe, was plunged into the 
$\mathrm{Cu}$ plates by aligning the center axis of the rotating tool with the center width of the groove filled with the mixture. A tungsten-based alloy is conventionally used for the tool in the friction stir welding of $\mathrm{Cu}$ which was demonstrated by Sun and Fujii (2011). The diameter of the tool shoulder was $15 \mathrm{~mm}$, and the diameter of the tool probe was 5 $\mathrm{mm}$ and its length was $0.5 \mathrm{~mm}$. The dimensions of the tool and groove were selected by trial and error because they depended on the capacity of the machine used. As shown in Fig. 1(c), after the rotating tool had been fully plunged into the $\mathrm{Cu}$ plates, it was held at the same position for $10 \mathrm{~s}$ before it was made to traverse. As shown in Fig. 1(d), the rotating tool was made to traverse with the rotation speed, traversing speed and tilt angle of $1000 \mathrm{rpm}, 50 \mathrm{~mm} / \mathrm{min}$ and $3 \mathrm{deg}$, respectively, throughout the experiment. The rotating tool was made to traverse a length of $50 \mathrm{~mm}$ on top of the groove with the mixture, then it was held at the final position for $10 \mathrm{~s}$ before being removed from the $\mathrm{Cu}$ plates. An overlapping multipass technique, which was recently demonstrated by Hangai et al. (2010) for fabricating aluminum foam and by El-Rayes and El-Danaf (2012) to modify the microstructural and mechanical properties of 6082-T6 aluminum alloy, was applied to thoroughly sinter the mixture, and the rotating tool was made to traverse the same region once again, as shown in Fig. 1(e). The depth of tool indentation was set to $1 \mathrm{~mm}$ below the height where the probe of the tool touched the surface of the $\mathrm{Cu}$ plates for the first pass, then the depth of tool indentation was increased by $1 \mathrm{~mm}$ for the second pass. The tool traversing conditions (i.e., rotation speed, traversing speed and pass number) were determined by trial and error process and according to Hangai et al. (2013a). Finally, the sintered mixture was machined to obtain a sample. The upper part, in the vicinity of the rotating tool as it was made to traverse, was machined to approximately $4 \mathrm{~mm}$ below the surface of the second pass to remove the $\mathrm{Cu}$ cover plates. Then, the sample was placed in a water bath at room temperature for $27 \mathrm{~h}$ to remove $\mathrm{NaCl}$. Eventually, three samples of $60 \mathrm{~mm}$ length, $10 \mathrm{~mm}$ width and 3.0-3.5 mm 
thickness with rounded corners of $5 \mathrm{~mm}$ radius were obtained; these samples had the same shape as but a different thickness from the groove. Three compression test specimens of $10 \mathrm{~mm} \times 10 \mathrm{~mm} \times 3.0-3.5 \mathrm{~mm}$ were machined from each sample.

Part of the powder mixture of $\mathrm{Al}$ and $\mathrm{NaCl}$ described above was subjected to SPS. The sintering temperature, pressure and time were $843 \mathrm{~K}, 20 \mathrm{MPa}$ and $600 \mathrm{~s}$, respectively, in accordance with those in the literature by Hakamada et al. (2005). The $\mathrm{NaCl}$ removal process used was the same as that in the FPC process. Three cylindrical samples with dimensions of $\phi=20 \mathrm{~mm} \times 13.7 \mathrm{~mm}$ were obtained. The obtained samples were cut by electrodischarge machining, and three $13 \mathrm{~mm} \times 13 \mathrm{~mm}$ compression specimens of $12 \mathrm{~mm}$ height were fabricated.

\subsection{Observation of pore structures}

X-ray CT observations were performed on the compression test specimens using an SMX-225CT microfocus X-ray CT system (Shimadzu Corporation). The X-ray source was tungsten. A cone-type X-ray CT system, which produces three-dimensional images, was employed. In this system, only one rotation of the specimen was sufficient to obtain a three-dimensional volume image, which consisted of a set of two-dimensional cross-sectional X-ray CT images with a slice pitch equal to the length of one pixel in the X-ray CT image. The resolution of each X-ray CT image was $512 \times 512$, and the pixel length was $31 \mu \mathrm{m}$. The X-ray tube voltage and current were $80 \mathrm{kV}$ and $20 \mu \mathrm{A}$, respectively. The porosity $p(\%)$ of the compression test specimens was evaluated from two-dimensional cross-sectional X-ray CT images using WinROOF image processing software (Mitani Corporation). An appropriate threshold was set to distinguish $\mathrm{Al}$ and the pores, and binarized X-ray CT images were established for the evaluation. The average $p$ of the two-dimensional cross-sectional X-ray CT images obtained in this study was considered to be the $p$ of the compression test specimens. Also, the $p$ of the 
compression test specimens was evaluated from the weight and dimension measurements.

The pore structures and cell walls of the fabricated $\mathrm{Al}$ foam were also observed by SEM at the front surface (i.e., in the vicinity of the traversing rotating tool) and back surface (i.e., the bottom part during the traversing of the tool).

\subsection{Compression tests}

Compression tests were carried out at room temperature in ambient air using an Autograph AG-100kNG universal testing machine (Shimadzu Corporation). The relative velocity between the cross head and the screw rod was set at $0.6 \mathrm{~mm} / \mathrm{min}$. At the same time, the compression deformation of the specimen was recorded on a digital video camera.

\section{Experimental Results and Discussion}

\subsection{Fabricated long $\mathrm{Al}$ foam plate}

Fig. 3 shows the fabricated $\mathrm{Al}$ foam sample before the dissolution of $\mathrm{NaCl}$. The left side of the figure shows the position where the rotating tool was first plunged into the $\mathrm{Cu}$ plates. The rotating tool traversed from the left side to the right side. The shape

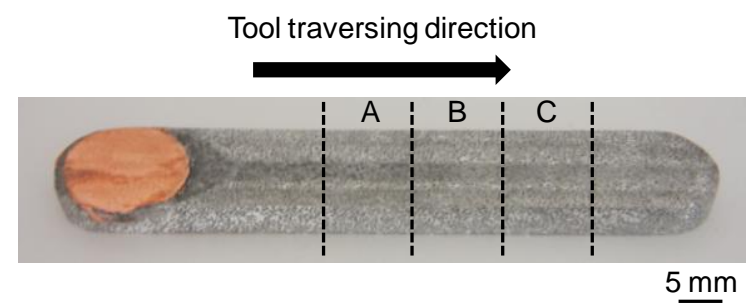

Fig. 3. Photograph of long Al foam plate fabricated by enhanced FPC process before the dissolution of $\mathrm{NaCl}$. 


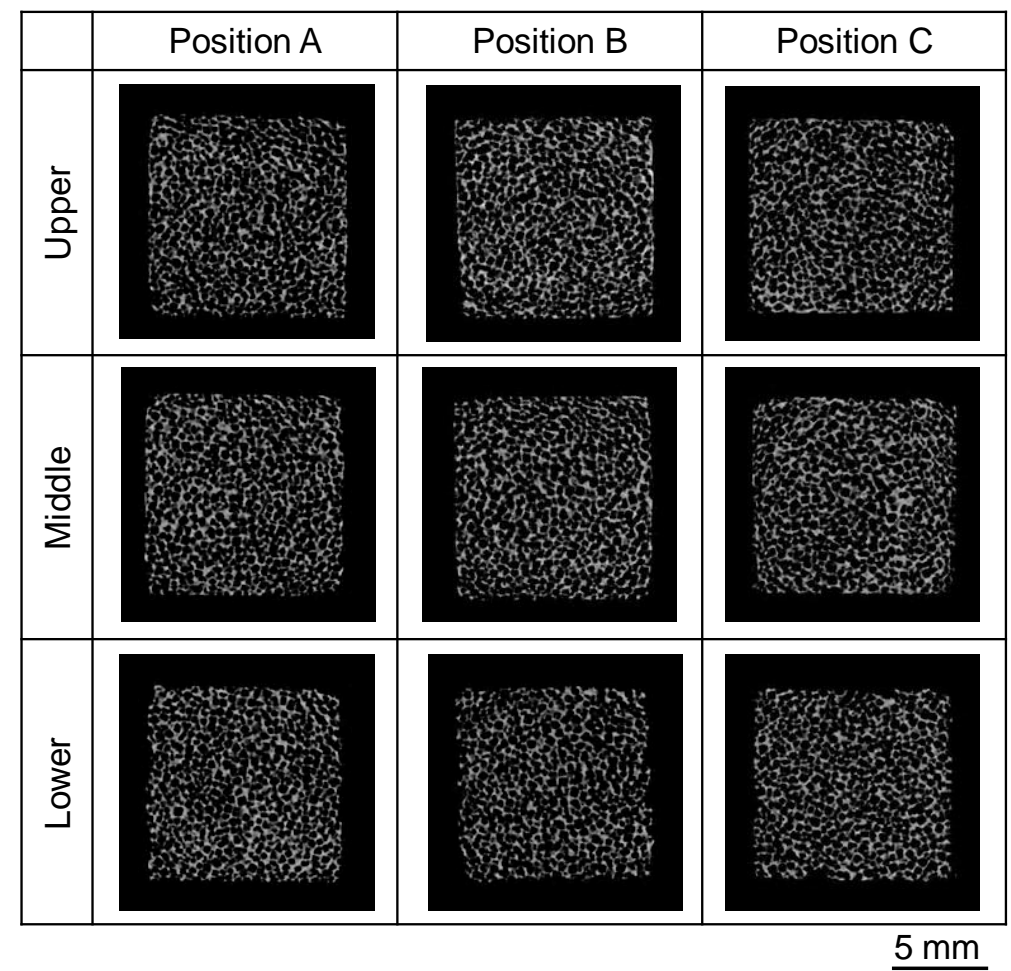

Fig. 4. Two-dimensional cross-sectional X-ray CT reconstructed images of pore structures of fabricated compression test specimens, taken at upper, middle and lower positions corresponding to positions A to $\mathrm{C}$.

of the obtained sample was almost the same as that of the groove. Almost the entire sample had a good surface, except at the starting position of the traversing tool (left side), where the $\mathrm{Cu}$ cover plate remained on the surface of the sample. This is because the entire cover plate with a thickness of $5 \mathrm{~mm}$ was pressed into the powder mixture at this position. In contrast, as the rotating tool traversed, although part of the cover plate was pressed into the powder mixture, the remainder of the cover plate was ejected as flash. The entire cover plate that was pressed into the powder mixture was machined and 


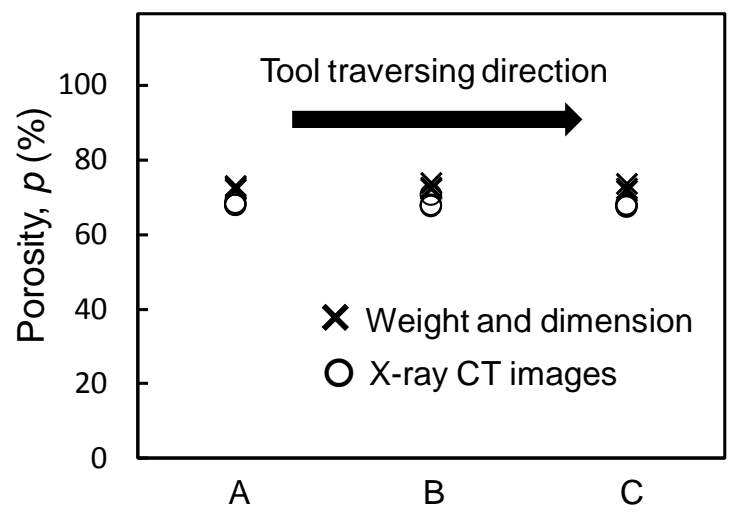

Fig. 5. Relationship between positions along traversing direction corresponding to positions $\mathrm{A}$ to $\mathrm{C}$ and porosities of compression test specimens. The porosities were evaluated by both weight and dimension measurements and using the X-ray CT images.

removed before the removal of $\mathrm{NaCl}$. However, the cover plate at the starting position of the sample was too thick to completely remove it to obtain a sample thickness of 3.0-3.5 mm. Compression test specimens were obtained from positions A to C in Fig. 3. Three samples were fabricated and three compression test specimens were obtained for each position.

\subsection{Pore structures of fabricated Al foam}

Fig. 4 shows typical two-dimensional cross-sectional X-ray CT reconstructed images of the pore structures of the compression test specimens, after the dissolution of $\mathrm{NaCl}$ taken at the upper, middle and lower positions in the specimens corresponding to positions $\mathrm{A}$ to $\mathrm{C}$. During the $\mathrm{NaCl}$ removal process, the sample retained its shape and no collapse was observed, indicating that strong bonding between the Al particles was 


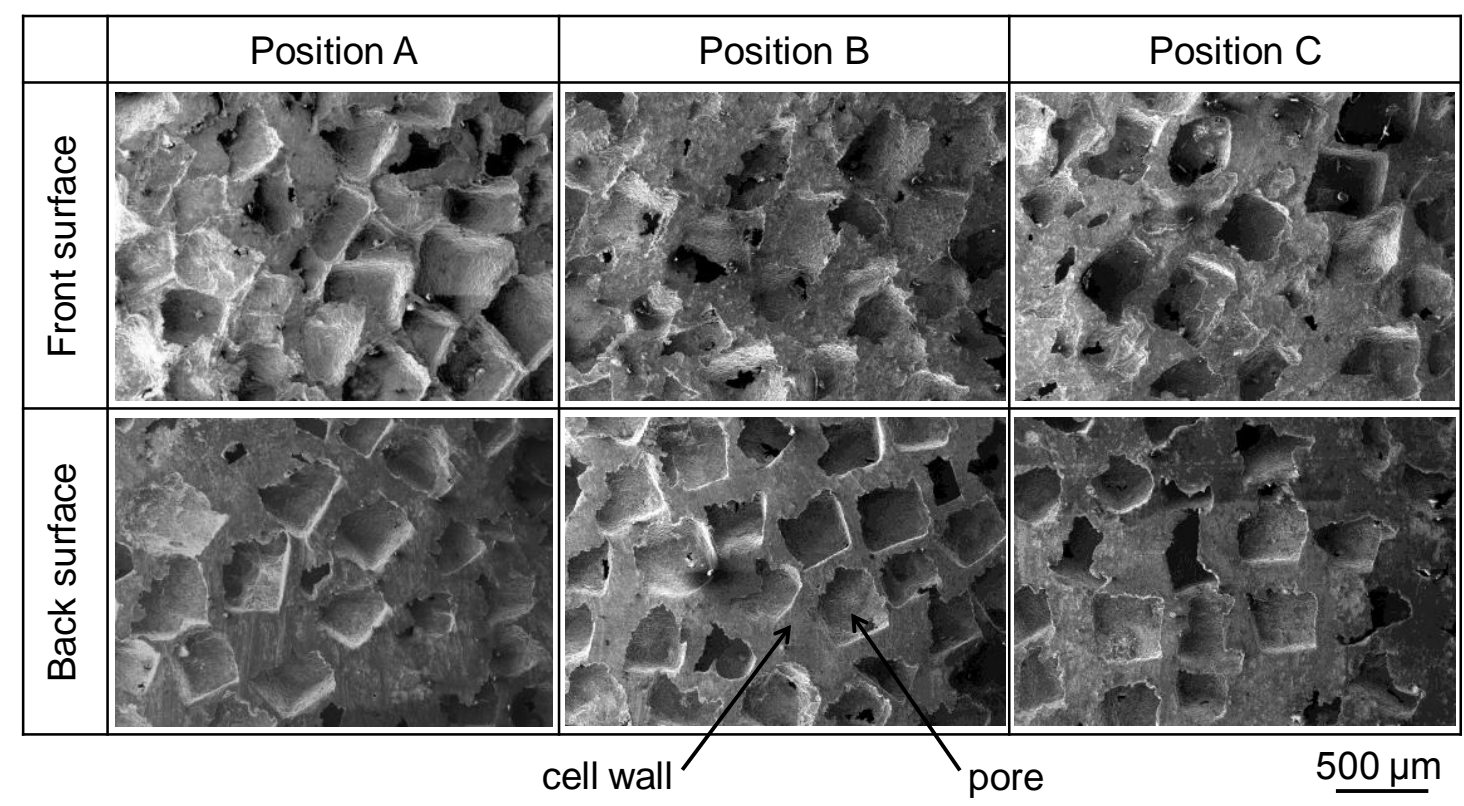

Fig. 6. SEM images of pore structures of compression test specimens taken at front and back surfaces of the specimens corresponding to positions A to $\mathrm{C}$.

achieved. The upper position of the specimens corresponds to the vicinity of the traversing rotating tool and the lower position is the bottom part during the traversing of the tool. Gray regions indicate cell walls of the Al foam and black regions indicate pores. It was shown that uniform pore structures can be obtained for all the specimens.

Fig. 5 shows the relationship between the positions along the traversing direction corresponding to positions $\mathrm{A}$ to $\mathrm{C}$ and the porosities of the compression test specimens. The porosities were evaluated by both weight and dimension measurements and using the X-ray CT images. It was found that the porosities were almost the same regardless of the position along the traversing direction. Note that the porosities evaluated by weight and dimension measurements were slightly higher than that evaluated using the $\mathrm{X}$-ray CT images. This is mainly due to the density of the Al powder compact of the cell 


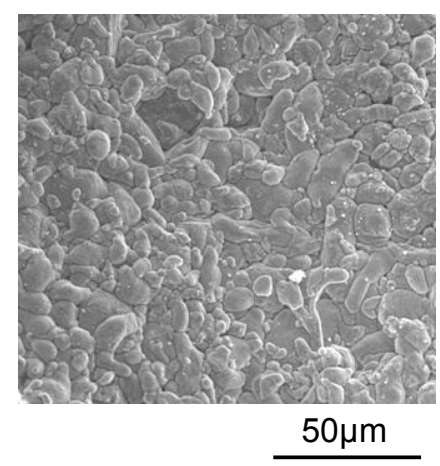

Fig. 7. Enlarged SEM image of cell wall shown in Fig. 6 at position B of back surface.

wall being lower than the theoretical density, and micropores in the cell wall cannot be observed owing to the low resolution of the X-ray CT images used in this study, whereby pores with a diameter below several tens of $\mu \mathrm{m}$ cannot be observed demonstrated by Hangai et al. (2009).

Fig. 6 shows SEM images of the pore structures of the compression test specimens taken at the front and back surfaces of the specimens corresponding to positions A to C. The front surface of the specimens corresponds to the vicinity of the rotating tool, and the back surface is the bottom part during the traversing of the tool. There was a concern that the surface of the specimens would be subjected to intense plastic deformation owing to the traversing of the rotating tool as in the previous studies by Hangai et al. (2012) and Hangai and Zushida (2013). However, elongated pores were seldom observed at the surface of the specimens, confirming that the obtained $\mathrm{Al}$ foam had pore structures similar to the $\mathrm{NaCl}$ morphology, as shown in Fig. 2(b), regardless of the height of the specimen and the position along the traversing direction. This is considered to be due to the existence of the groove-shaped $\mathrm{Cu}$ cover plate that prevented the direct contact between the rotating tool and the mixture, in contrast to the previous 

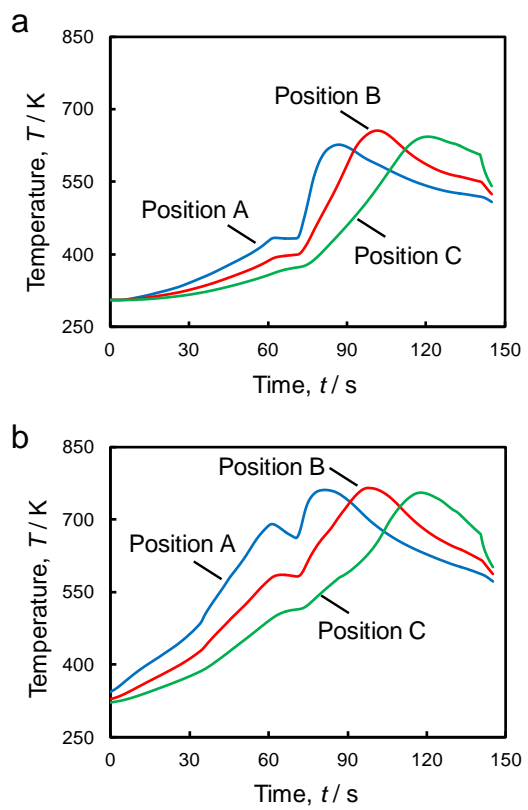

Fig. 8. Relationship between time $t$ and temperature $T$ during enhanced FPC process for (a) first pass and (b) second pass.

studies in which the rotating tool was in direct contact with the mixture.

Fig. 7 shows an enlarged SEM image of the cell wall shown in Fig. 6 at position B of the back surface. It can be seen that the Al particles, which had an irregular and elongated shape, shown in Fig. 2(a) almost retained their shape, namely it is considered that no melt of the Al particles occurred. No voids can be seen at this magnification, and the particles were considered to be bonded appropriately.

\subsection{Temperature during enhanced FPC process}

Fig. 8 shows the relationship between the time $t$ and temperature $T$ during the 
enhanced FPC process for the first pass (Fig. 8(a)) and the second pass (Fig. 8(b)). $t$ is the time elapsed from when the tool first came into contact with the surface of the $\mathrm{Cu}$ plates when the rotating tool plunged into the $\mathrm{Cu}$ plates before the tool was made to traverse. A thermocouple was placed at the middle height and center width of the powder mixture in the groove at positions $\mathrm{A}$ to $\mathrm{C}$ to measure the temperature during the enhanced FPC process. First, the indentation of the tool gradually increased the temperature up to $t=60 \mathrm{~s}$ owing to the friction heat generated between the tool and the $\mathrm{Cu}$ plates and the increase in the contact area between them. The temperature at position A, which was in the vicinity of the rotating tool indentation, first increased. The transfer of the generated heat to the $\mathrm{Cu}$ plates increased the temperatures at positions $\mathrm{B}$ and $\mathrm{C}$. The rotating tool that fully plunged into the $\mathrm{Cu}$ plates was held at the same position from $t=60 \mathrm{~s}$ to $70 \mathrm{~s}$. This holding of the tool caused temperature to be almost constant, owing to the balance between the amount of friction heat generated and the amount of heat released from the surface of the $\mathrm{Cu}$ plates. Then, the tool was made to traverse from $t=70 \mathrm{~s}$ to $120 \mathrm{~s}$. The temperature rapidly increased at position $\mathrm{A}$ as the tool approached the thermocouple located at position A from $t=70 \mathrm{~s}$ to $80 \mathrm{~s}$. After the tool passed through position A, the temperature at position A gradually decreased because the tool, at which friction heat was generated, moved further away and the amount of heat released from the surface of the $\mathrm{Cu}$ plates increased. The temperatures at positions $\mathrm{B}$ and $\mathrm{C}$ increased gradually as the tool approached these positions owing to the transfer of heat to the $\mathrm{Cu}$ plates and then decreased gradually after as the tool passed through these positions. After $t=120 \mathrm{~s}$, the tool was held at the end position for $10 \mathrm{~s}$, then the tool was removed upward, causing the temperature to decrease rapidly. The tendencies of the temperature to increase and decrease during the FPC process are almost the same regardless of the position along the traversing direction. In the second pass, the temperature behaved similarly to that in the first pass but was higher. This is due to the 


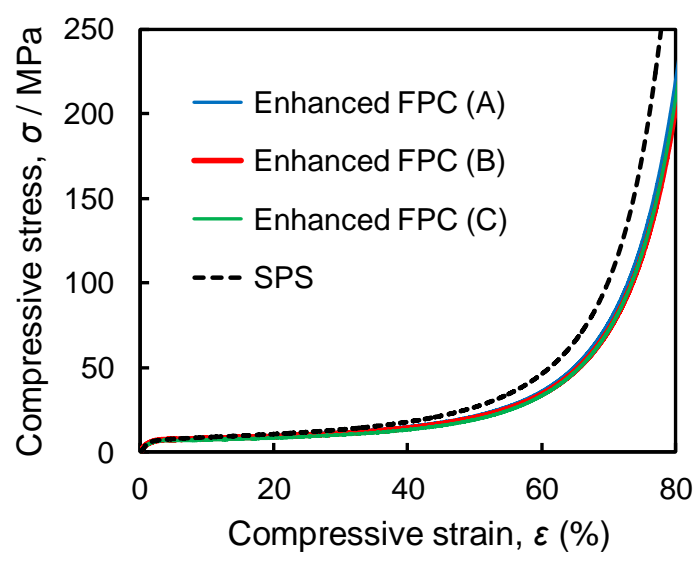

Fig. 9. Stress-strain curves for Al foam plates fabricated by enhanced FPC, at position A through C, and by SPS.

increased indentation depth; it was observed, in a previous study demonstrated by Hangai et al. (2013a), that the temperature increased with increasing indentation depth when a rotating tool was plunged vertically into a $\mathrm{Cu}$ plate. The maximum temperature, which was achieved when the tool traversed immediately above each thermocouple, was determined to be approximately $650 \mathrm{~K}$ for the first pass and approximately $770 \mathrm{~K}$ for the second pass, regardless of the position along the traversing direction. The temperature in the second pass was higher than that of the FPC process without the traversing tool, which was indicated to be $670 \mathrm{~K}$ in the previous study. This is considered to be due to the effect of the existence of the bottom part of the groove below the mixture in this study where the rate of heat transfer was higher than that in the absence of the bottom part of the hole below the mixture, as was observed in the previous study. Therefore, it is assumed that the powder temperature in this study was sufficient to ensure the bonding of Al particles as a result of the traversing of the tool. 

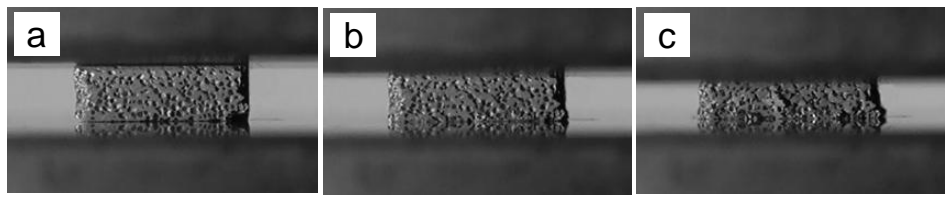

$\underline{5 \mathrm{~mm}}$

Fig. 10. Deformation images for different strains during compression tests of $\mathrm{Al}$ foam plate fabricated by enhanced FPC, at position B. (a) $\varepsilon=0 \%$, (b) $\varepsilon=20 \%$ and (c) $\varepsilon=$ $40 \%$.

Clearly, much more extensive investigations are necessary concerning the $\mathrm{Cu}$ plate shape and the observed temperature of the powder.

\subsection{Mechanical properties}

Fig. 9 shows typical stress-strain curves under the compression of the Al foam specimen fabricated by the enhanced FPC at position A through C and SPS. Three specific regions, namely, the elastic region at the initial stage, the plateau region with a nearly constant stress up to a large strain and the densification region where the stress increased markedly, can be clearly observed. It can be seen that the Al foam specimen fabricated by the enhanced FPC exhibited almost similar stress-strain curves to that fabricated by SPS. Also, these stress-strain curves are similar to those of other typical Al foam samples reported in the literature by Gibson (2000) and by Miyoshi et al. (2000), and other open-cell Al foam samples obtained by different sintering processes using an electric furnace or an SPS via the sintering and dissolution process, as reported in the literature by Zhao and Sun (2001), Sun and Zhao (2003) and Hakamada et al. (2007).

Fig. 10 shows typical deformation images of the $\mathrm{Al}$ foam fabricated by the enhanced 


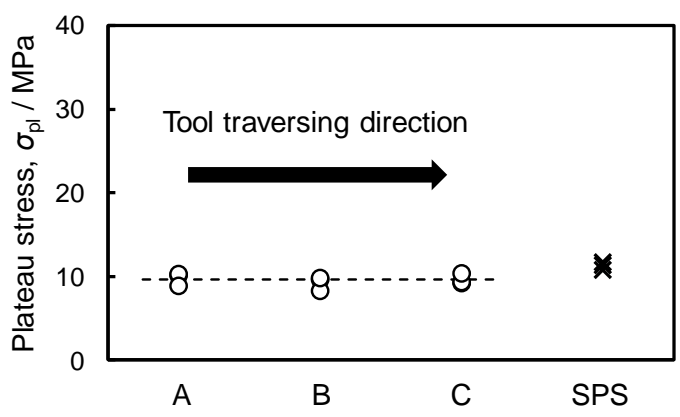

Fig. 11. Relationship between position along the traversing direction and plateau stress $\sigma_{\mathrm{pl}}$ of each compression test specimen along with $\sigma_{\mathrm{pl}}$ of $\mathrm{Al}$ foam sample fabricated by SPS.

FPC at position B for different strains during compression tests. The upper part of the images corresponds to the upper position of the specimen in the vicinity of the traversing rotating tool. It can be seen that the fabricated $\mathrm{Al}$ foam exhibited ductile fracture. This deformation behavior was observed in all $\mathrm{Al}$ foam specimens fabricated in this study by the enhanced FPC and by SPS. No brittle fracture, which would have resulted in a fluctuation in plateau stress during the compression tests owing to the poor bonding of $\mathrm{Al}$ particles demonstrated by Hakamada et al. (2005), was observed. Consequently, it is considered that good bonding between $\mathrm{Al}$ particles was achieved.

Fig. 11 shows the relationship between the position along the traversing direction and plateau stress $\sigma_{\mathrm{pl}}$ of each compression test specimen along with $\sigma_{\mathrm{pl}}$ of the $\mathrm{Al}$ foam specimen fabricated by SPS. $\sigma_{\mathrm{pl}}$ was defined as the average stress for a strain of $20-30 \%$ of the stress-strain curves shown in Fig. 9 as suggested by JIS-H-7902 (2008). The results of three compression tests for each position were shown. It was shown that $\sigma_{\mathrm{pl}}$ remained almost the same regardless of the position of the sample. Although there were 
slight differences between the $\sigma_{\mathrm{pl}}$ values exhibited by the $\mathrm{Al}$ foam specimens fabricated by the enhanced FPC and SPS, one of the reasons for which was considered to be the effect of the geometry of the specimens, it was shown that the Al foam specimen fabricated by the enhanced FPC exhibited similar mechanical properties to that fabricated by SPS. Consequently, it was found that a long Al foam plate with uniform pore structures and mechanical properties can be fabricated by traversing the tool.

It is expected that a larger $\mathrm{Al}$ foam plate without size limitation can be easily obtained by the enhanced FPC process. By increasing the distance that the tool traverses, a longer Al foam plate can be expected. By a multipass technique which was demonstrated by Sato et al. (2005), in which the rotating tool is shifted perpendicularly to the traversing direction after each pass, a wider Al foam plate can also be expected.

\section{Conclusion}

In this study, an enhanced FPC process based on the sintering and dissolution process was proposed for fabricating a large plate of $\mathrm{Al}$ foam. In this process, the rotating tool plunged into the $\mathrm{Cu}$ plate die filled with the powder mixture of $\mathrm{Al}$ and $\mathrm{NaCl}$ during the FPC process was made to traverse perpendicularly to the direction of plunging. In the FPC process, no external heat source, such as an electric furnace or an SPS, was used for fabricating $\mathrm{Al}$ foam, other than the friction heat generated by the rotating tool traversed on top of the $\mathrm{Cu}$ plate die filled with the powder mixture.

It was found that a long $\mathrm{Al}$ foam plate can be fabricated with a length equal to the tool traversing length. By X-ray CT and SEM observations of the pore structures of the fabricated $\mathrm{Al}$ foam plate, it was found that the entire sample had a pore structure that was similar to the $\mathrm{NaCl}$ morphology, regardless of the position along the traversing direction.

The Al foam plate fabricated by the enhanced FPC process had similar stress-strain 
curves to that fabricated by SPS and exhibited ductile fracture regardless of the position along the traversing direction. This is considered to be attributed to the good bonding between $\mathrm{Al}$ particles in the entire sample. The $\mathrm{Al}$ foam plate fabricated by the enhanced FPC process exhibited almost the same plateau stress regardless of the position along the traversing direction and indicated a similar plateau stress to that of the $\mathrm{Al}$ foam specimen fabricated by SPS.

Consequently, it was shown that $\mathrm{Al}$ foam with uniform pore structures and mechanical properties regardless of the position in the sample can be obtained by the enhanced FPC process.

\section{Acknowledgments}

The authors thank Professor T. Komoto and Professor H. Kumehara, Monodukuri Research Organization (MRO), for their helpful advices on conducting the experiments. This work was partly financially supported by the Industrial Technology Research Grant Program in 2009 from the New Energy and Industrial Technology Development Organization (NEDO) of Japan, Adaptable and Seamless Technology Transfer Program through target-driven R\&D in 2013 from the Japan Science and Technology Agency (JST) of Japan, and Research Grant Program 2013 from Gunma University Foundation for Science and Technology. 


\section{References}

Arakawa, Y., Kobashi, M., Kanetake, N., 2013. Foaming behavior of long-scale Al-Ti intermetallic foam by SHS mode combustion reaction. Intermetallics 41, 22-27.

Banhart, J., 2001. Manufacture, characterisation and application of cellular metals and metal foams. Prog. Mater. Sci. 46, 559-632.

El-Rayes, M.M., El-Danaf, E.A., 2012. The influence of multi-pass friction stir processing on the microstructural and mechanical properties of Aluminum Alloy 6082. J. Mater. Process. Technol. 212, $1157-1168$

Gibson, L.J., 2000. Mechanical behavior of metallic foams. Annu. Rev. Mater. Sci. 30, 191-227.

Hakamada, M., Kuromura, T., Chino, Y., Yamada, Y., Chen, Y., Kusuda, H., Mabuchi, M., 2007. Monotonic and cyclic compressive properties of porous aluminum fabricated by spacer method. Mater. Sci. Eng. A 459, 286-293.

Hakamada, M., Yamada, Y., Nomura, T., Chen, Y.Q., Kusuda, H., Mabuchi, M., 2005. Fabrication of porous aluminum by spacer method consisting of spark plasma sintering and sodium chloride dissolution. Mater. Trans. 46, 2624-2628.

Hangai, Y., Maruhashi, S., Kitahara, S., Kuwazuru, O., Yoshikawa, N., 2009. Nondestructive Quantitative Evaluation of Porosity Volume Distribution in Aluminum Alloy Die Castings by Fractal Analysis. Metall. Mater. Trans. A 40, 2789-2793.

Hangai, Y., Utsunomiya, T., Hasegawa, M., 2010. Effect of tool rotating rate on foaming properties of porous aluminum fabricated by using friction stir processing. J. Mater. Process. Technol. 210, 288-292.

Hangai, Y., Yoshida, H., Kuwazuru, O., Yoshikawa, N., 2013a. Effect of die material on compressive properties of open-cell porous aluminum fabricated by friction powder compaction process. Mater. Trans. 54, 1057-1059.

Hangai, Y., Yoshida, H., Yoshikawa, N., 2012. Friction Powder Compaction for Fabrication of Open-Cell Aluminum Foam by the Sintering and Dissolution Process Route. Metall. Mater. Trans. A 43, 802-805. Hangai, Y., Zushida, K., 2013. Fabrication of large-scale porous aluminum by enhanced friction powder 
compaction process through traversing tool based on sintering and dissolution process. Mater. Trans., in press.

Hangai, Y., Zushida, K., Fujii, H., Ueji, R., Kuwazuru, O., Yoshikawa, N., 2013b. Friction powder compaction process for fabricating open-celled porous $\mathrm{Cu}$ by sintering-dissolution process route using $\mathrm{NaCl}$ space holder. Mater. Sci. Eng. A 585, 468-474.

Inada, K., Fujii, H., Ji, Y.S., Sun, Y.F., Morisada, Y., 2010. Effect of gap on FSW joint formation and development of friction powder processing. Science and Technology of Welding and Joining 15, 131-136. JIS-H-7902, 2008. Method for compressive test of porous metals. Japanese Standards Association.

Kobashi, M., Miyake, S., Kanetake, N., 2013. Hierarchical open cellular porous TiAl manufactured by space holder process. Intermetallics 42, 32-34.

Li, B., Shen, Y.F., Luo, L., Hu, W.Y., 2013. Fabrication of TiCp/Ti-6Al-4V surface composite via friction stir processing (FSP): Process optimization, particle dispersion-refinement behavior and hardening mechanism. Mater. Sci. Eng. A 574, 75-85.

Mishra, R.S., Ma, Z.Y., Charit, I., 2003. Friction stir processing: a novel technique for fabrication of surface composite. Mater. Sci. Eng. A 341, 307-310.

Miyoshi, T., Itoh, M., Akiyama, S., Kitahara, A., 2000. ALPORAS aluminum foam: Production process, properties, and applications. Adv. Eng. Mater. 2, 179-183.

Morisada, Y., Fujii, H., Nagaoka, T., Nogi, K., Fukusumi, M., 2007. Fullerene/A5083 composites fabricated by material flow during friction stir processing. Compos. Pt. A-Appl. Sci. Manuf. 38, 2097-2101.

Qian, J.W., Li, J.L., Xiong, J.T., Zhang, F.S., Lin, X., 2012. In situ synthesizing Al3Ni for fabrication of intermetallic-reinforced aluminum alloy composites by friction stir processing. Mater. Sci. Eng. A 550, $279-285$

Rejil, C.M., Dinaharan, I., Vijay, S.J., Murugan, N., 2012. Microstructure and sliding wear behavior of AA6360/(TiC+B4C) hybrid surface composite layer synthesized by friction stir processing on aluminum substrate. Mater. Sci. Eng. A 552, 336-344. 
Sato, Y.S., Park, S.H.C., Matsunaga, A., Honda, A., Kokawa, H., 2005. Novel production for highly formable Mg alloy plate. J. Mater. Sci. 40, 637-642.

Sun, D.X., Zhao, Y.Y., 2003. Static and dynamic energy absorption of Al foams produced by the sintering and dissolution process. Metall. Mater. Trans. B 34, 69-74.

Sun, Y.F., Fujii, H., 2011. The effect of SiC particles on the microstructure and mechanical properties of friction stir welded pure copper joints. Mater. Sci. Eng. A 528, 5470-5475.

Surace, R., De Filippis, L.A.C., Ludovico, A.D., Boghetich, G., 2009. Influence of processing parameters on aluminium foam produced by space holder technique. Mater. Des. 30, 1878-1885.

Zhao, Y.Y., Sun, D.X., 2001. A novel sintering-dissolution process for manufacturing Al foams. Scr. Mater. 44, 105-110. 